\title{
Author Correction: Experimental evidence for the existence of a second partially-ordered phase of ice VI
}

\author{
Ryo Yamane (D), Kazuki Komatsu (1D, Jun Gouchi, Yoshiya Uwatoko (D), Shinichi Machida, Takanori Hattori, \\ Hayate Ito \& Hiroyuki Kagi
}

Correction to: Nature Communications https://doi.org/10.1038/s41467-021-21351-9, published online 18 February 2021.

The original version of the Supplementary information associated with this Article contained errors in Supplementary Table 1. The correct version of the 17th row of the 2 nd column states ' $0.211(2)$ ' instead of the original, incorrect ' $0.221(4)$ '; the correct version of the 14th row of the 3rd column states ' $0.954(2)$ ' instead of the original, incorrect ' $0.954(4)$ '; the correct version of the 19th row of the 5th column states ' $0.43(3)$ ' instead of the original, incorrect ' $0.45(3)$ '.

The original version of the Supplementary information associated with this Article also contained an error in Supplementary Table 2. The correct version of the 11th row of the 4th column states ' $0.43(3)$ ' instead of the original, incorrect ' $0.45(3)$ '.

The original version of the Supplementary information associated with this Article also contained errors in Supplementary Table 3. The correct version of the 14th row of the 2 nd column states ' $0.705(3)$ ' instead of the original, incorrect ' $0.468(2)$ '; the correct version of the 14th row of the 3rd column states ' $0.684(3)$ ' instead of the original, incorrect '0.971(3)'; the correct version of the 14th row of the 4 th column states ' $0.134(5)$ ' instead of the original, incorrect ' $0.130(6)$ '; the correct version of the 15th row of the 3rd column states '0.971(3)' instead of the original, incorrect ' $0.035(2)$ '.

The HTML has been updated to include a corrected version of the Supplementary information.

Published online: 15 March 2021

\section{Additional information}

Supplementary information The online version contains supplementary material available at https://doi.org/10.1038/s41467-021-22085-4.

Open Access This article is licensed under a Creative Commons Attribution 4.0 International License, which permits use, sharing, adaptation, distribution and reproduction in any medium or format, as long as you give appropriate credit to the original author(s) and the source, provide a link to the Creative Commons license, and indicate if changes were made. The images or other third party material in this article are included in the article's Creative Commons license, unless indicated otherwise in a credit line to the material. If material is not included in the article's Creative Commons license and your intended use is not permitted by statutory regulation or exceeds the permitted use, you will need to obtain permission directly from the copyright holder. To view a copy of this license, visit http://creativecommons.org/licenses/by/4.0/.

(C) The Author(s) 2021 